\title{
DETERMINATION OF BATHYMETRY USING MARINE RADAR IMAGES OF WAVES
}

\author{
Paul S.Bell ${ }^{1}$
}

\begin{abstract}
This paper illustrates a method of calculating bathymetric maps of shallow water areas $(<20 \mathrm{~m}$ depth) using an analysis of wave properties determined from an analysis of marine radar image sequences of waves. Water depths determined using this corrected for tidal variation in water level are compared quantitatively to conventional surveys. Two case studies are shown from the COAST3D project field sites at Egmond aan Zee in the Netherlands and at Teignmouth in the United Kingdom.
\end{abstract}

\section{INTRODUCTION}

Shallow water coastal areas are amongst the most commercially important regions of the sea for human activity. Virtually all research carried out at such sites requires accurate bathymetric surveys both for experimental purposes and as the primary input to numerical models. However, surveys are expensive, and are frequently limited by the times when survey vessels can operate. This paper describes a technique that with further development could be used to supply bathymetric surveys of such areas remotely and on a daily or even hourly basis using data sequences recorded from marine radar.

Marine radars have been used for the remote determination of offshore 2-D wave spectra on both a research and commercial basis for some years now (Borge et al 1999). Their use in coastal waters has been complicated by the non-uniform behaviour of waves over varying bathymetry in shallow water. Recently this complication has been turned to an advantage (Bell 1998, Bell 1999 and Hessner 1999). Wavelengths of the waves have been mapped from radar image sequences recorded at two coastal areas as part of the EU funded COAST3D study (Soulsby 1998). These data have been used in a bathymetric inversion technique based on linear wave theory to produce estimated bathymetric maps of the scanned areas. Calculated water depth maps, with the tidal levels subtracted to give water depths to chart datum, have been compared to surveys carried out by commercial survey vessels

The two case studies reported here are located at Egmond in the Netherlands - a

1 P.S.Bell, Proudman Oceanographic Laboratory, Bidston Observatory, Prenton, Wirral, United Kingdom, CH43 7RA. E-mail: psb@ pol.ac.uk 
long straight beach with a double bar system, and Teignmouth in the UK - a complex area including a river outflow, an extensive sandbar system and a linear beach.

The accuracy of the bathymetric estimates were determined in both cases, the results of which generally showed very good agreement with the survey data. There are two circumstances where the depths calculated from the inversion algorithm were not in agreement with the surveys. The first was in very shallow water of less than 3 metres depth where non-linear behaviour of large waves in shallow water was causing an overestimate of the water depth. The second was where currents caused a Doppler shift of the wave frequencies, and so induced errors in the inversion. Further work is intended to address these problem areas.

\section{EXPERIMENTAL PROCEEDURE}

A standard horizontally polarised X-band $(3 \mathrm{~cm}$ wavelength) marine radar was mounted approximately 10 metres above mean sea level overlooking the areas of study. A PC based recording system was used automatically each hour to digitise and store 64 images in a row at approximately 2.4 second intervals at a range resolution of $7.5 \mathrm{~m}$ and angular intervals of approximately $1^{\circ}$. These image sequences of approximately 2.5minutes in length were later interpolated onto a geographically aligned cartesian grid with $7.5 \mathrm{~m}$ pixels. The initial alignment of the images was carried out by hand using the radar reflections of targets with known DGPS positions and the location of the radar transmitter.

In the first study at Egmond aan Zee the radar was mounted on a purpose built tower on a field station at the back of the beach (Figure 1).

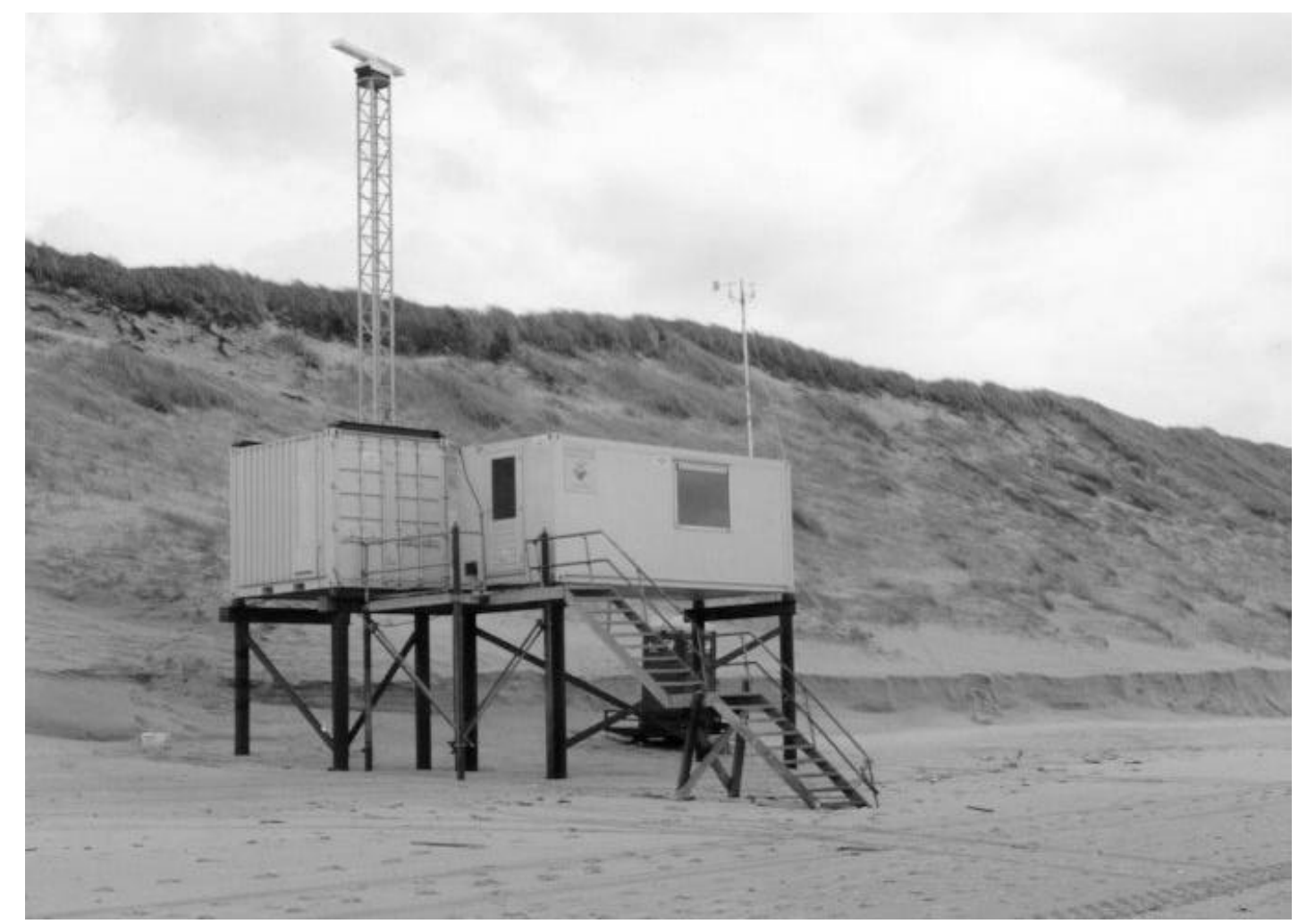

Figure 1. A photograph of the radar on a tower at Egmond.

Figure 2 shows a contour map of the area of sea which was studied. Conventional ship surveys for the deeper water and Water en Stand Profiler (WESP; Ruessink et al, 
2000) data for the shallower areas are combined to provide full coverage of the study area.

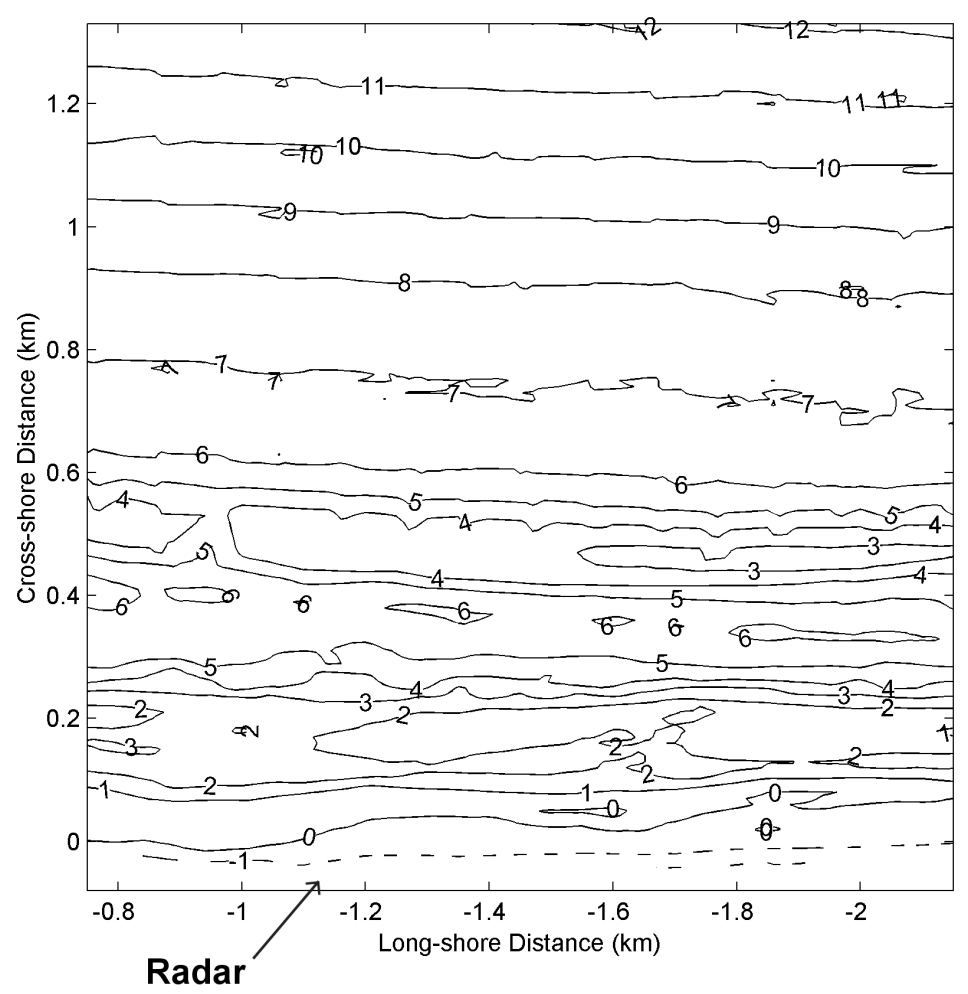

Figure 2. A contour plot of the bathymetry at Egmond with the location of the radar indicated by the arrow.

At the Teignmouth site the radar was mounted on the roof of a Victorian pier about $10 \mathrm{~m}$ above mean sea level. The computer monitors and radar monitor were housed in a room within the pier. Figure 3 shows the pier with the radar on the roof. Figure 4 shows a contour plot of a conventional ship survey of the area carried out at the start of the experiment.

\section{ANALYSIS OF IMAGE SEQUENCES}

Timestacks of each individual pixel were passed through an FFT to isolate individual wave frequencies. Each frequency plane was then analysed to map the wavelength of the waves at that frequency using image analysis techniques. Nine frequency planes centred around the peak wave frequency were analysed in this manner and the results for each Fourier layer inverted using linear wave theory to determine the water depth corresponding to that wave behaviour. The linear wave theory used in the inversion depends on the linear dispersion of waves in shallow water, but does not take into account the Doppler shift of currents or the non-linear effects of waves in very shallow water or the effects of breaking waves. The errors that these inadequacies of the depth inversion inevitably introduce will be pointed out in the results section of this paper, and will be addressed in future work. The depth estimates for each Fourier layer were then averaged to give a single depth estimate for that pixel. 


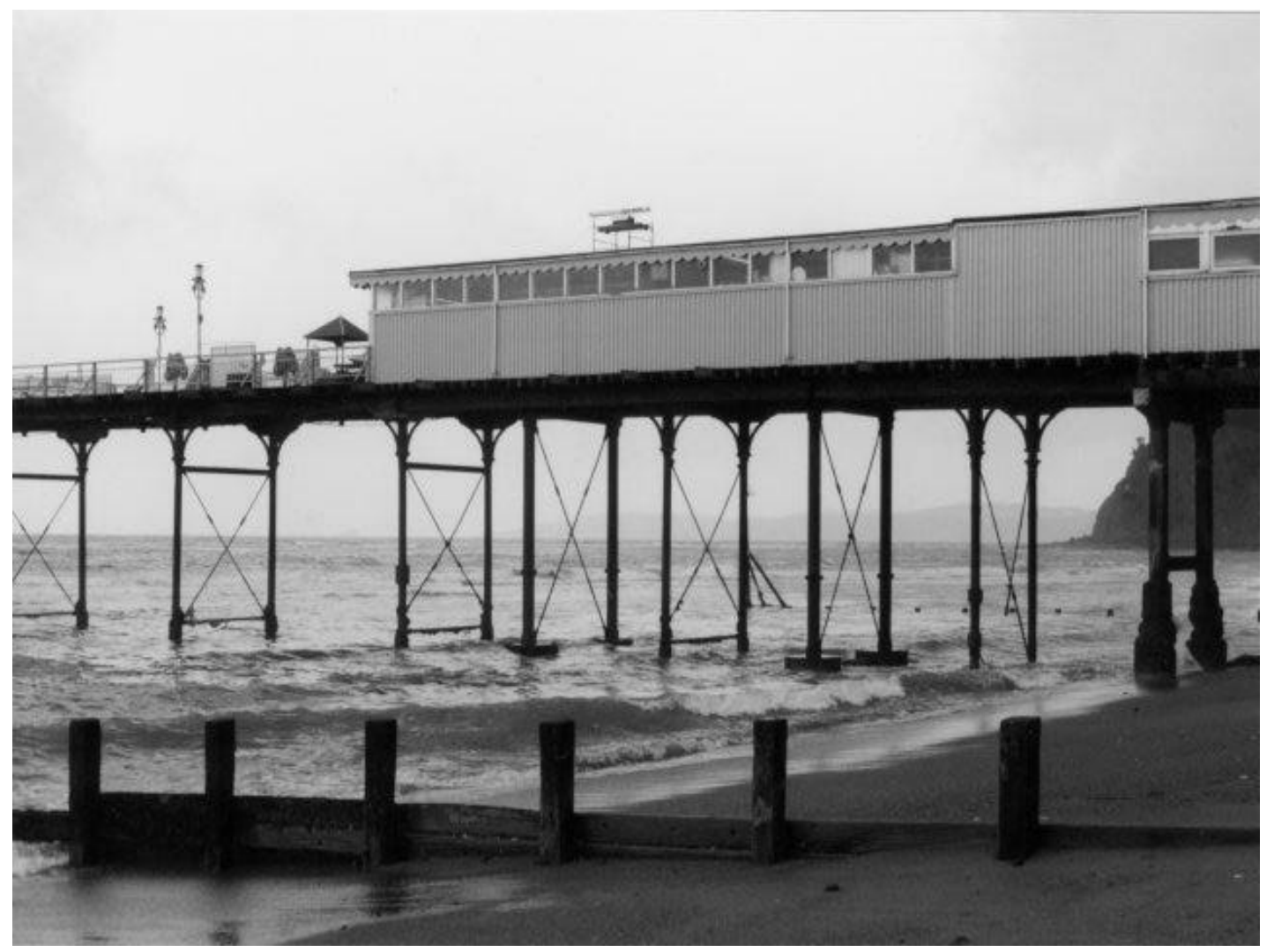

Figure 3. A photograph of the radar on Teignmouth Pier.

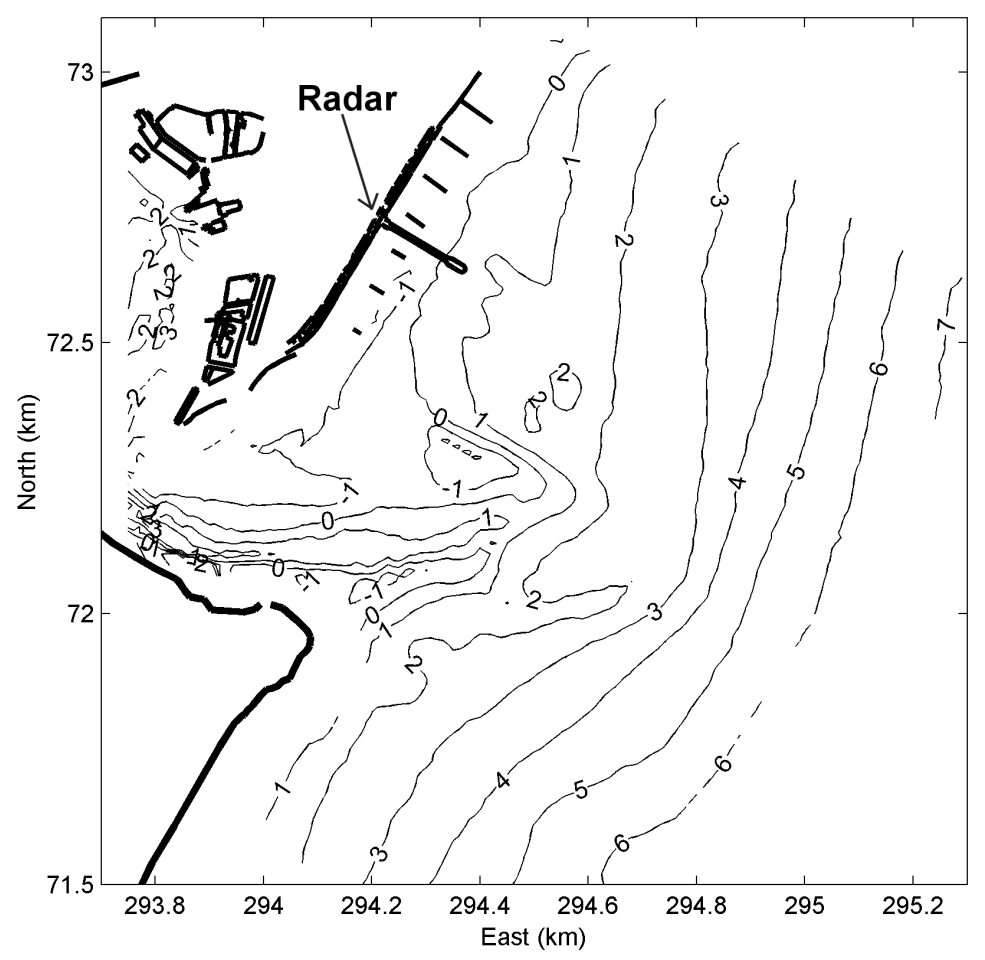

Figure 4. A contour plot of the bathymetry at Teignmouth, with the coastline marked as the heavy line and the location of the radar indicated by the arrow.

The water depth maps generated for each hourly capture often have gaps in them due to poor signal returns or particularly complex wave behaviour, so the results from a number of hourly records were combined to produce daily bathymetric maps. Tidal 
levels from nearby tide gauges were subtracted from the water depths at each hour, so that the resulting depths were referenced to the local chart datum. The daily averaged depth maps were then compared directly with the conventional surveys.

\section{RESULTS}

\section{Egmond aan Zee}

Bathymetric estimates were determined from hourly records of radar data for 12 hours on $16^{\text {th }}$ October 1998 . The tidal water levels measured by a tide gauge were subtracted from each of these estimates, and the resulting depths to chart datum were averaged to give a mean bathymetric map for that 12 hours. The depths determined from this technique were compared directly with the combined ship and WESP bathymetric maps. Figure 5 shows a scatter plot of this comparison, with the ideal results of the radar estimates and the survey being equal shown as the $\mathrm{y}=\mathrm{x}$ line.

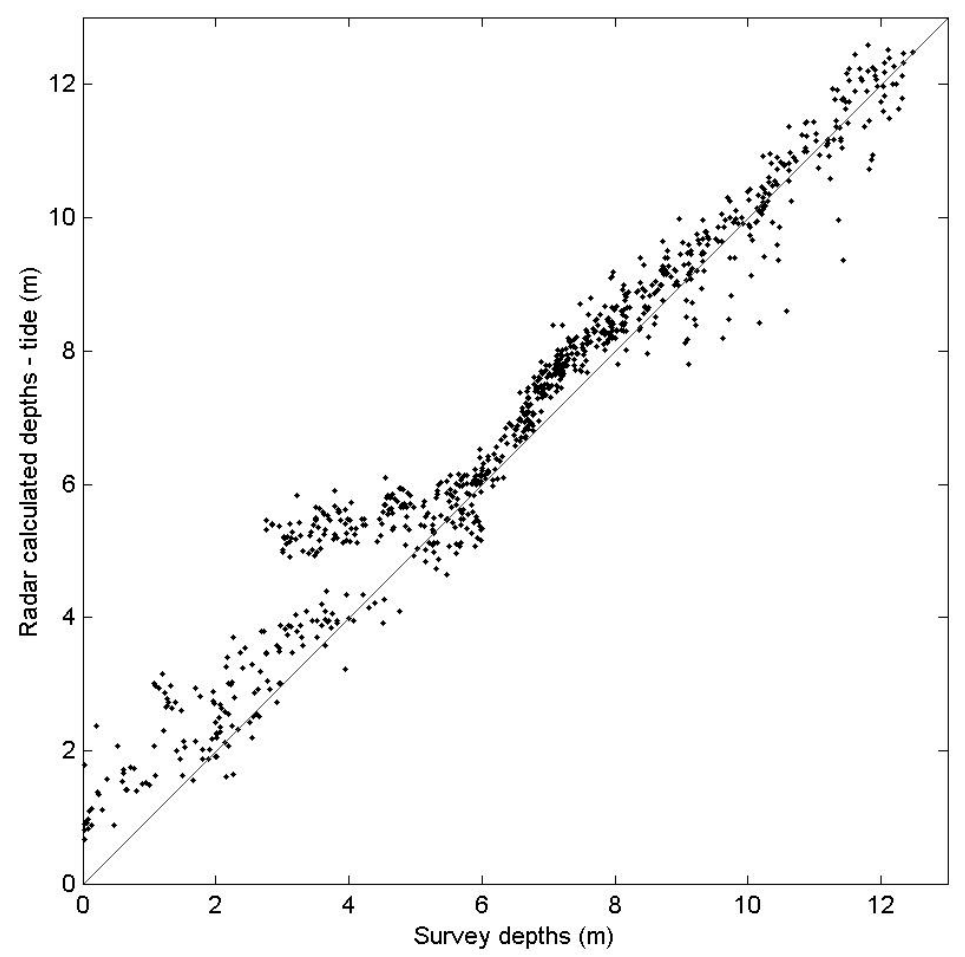

Figure 5. A plot of radar determined depths minus tidal levels compared to survey depths.

In general the radar determined the water depth within $1 \mathrm{~m}$ of the chart depths in up to 12 metres of water. However, there was an increased error over the outer bars where the rapid change in water depth and relatively shallow water resulted in non-linear wave behaviour. This led to the overestimate of the depth by the radar with depths between 4-5 metres at the outer bar, and again in the very shallow water near the beach.

\section{Teignmouth}

The hourly results of the radar analysis for the day of $12^{\text {th }}$ November1999 had the tidal elevations removed and were averaged in the same way as the Egmond data. The results of the comparison between the radar estimated depths and the survey depths are shown in Figure 6. 


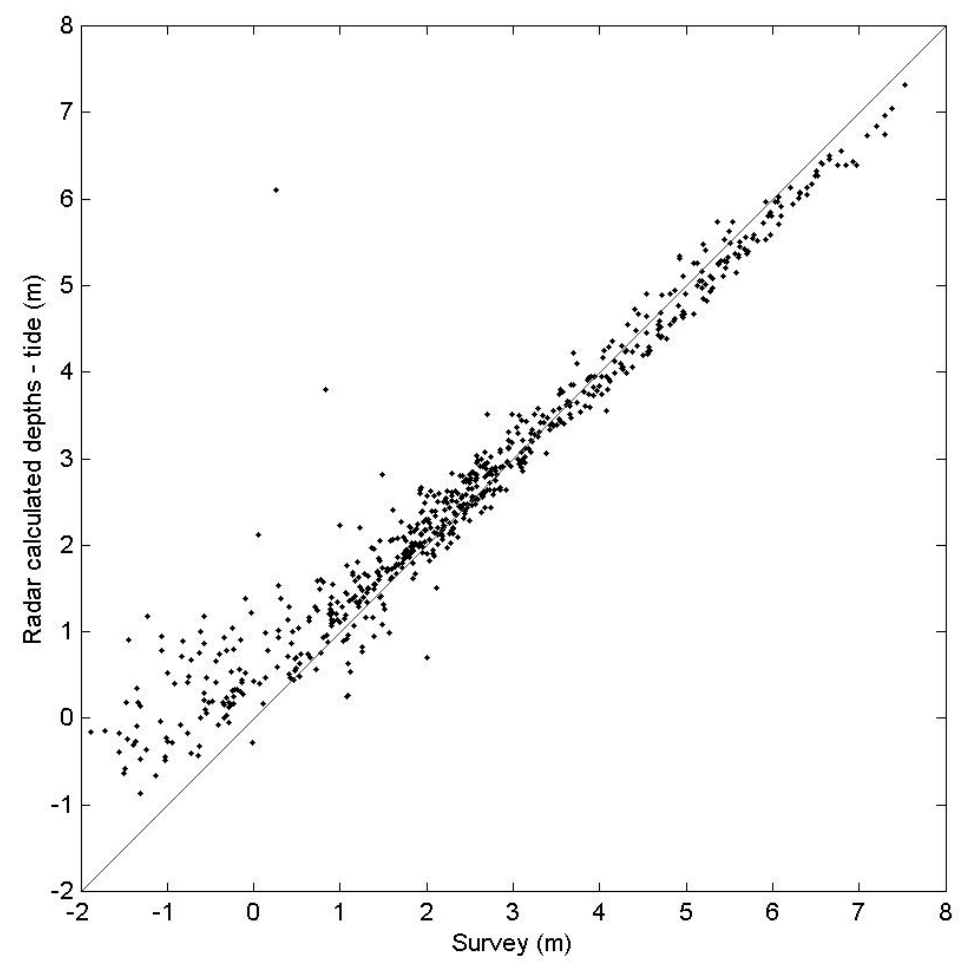

Figure 6. A plot of radar determined depths for Teignmouth (minus tidal levels) compared to survey depths.

As with the Egmond data, the results from Teignmouth show very good agreement with the survey depths. Similar errors are also visible in the very shallow water where the radar is overestimating the water depths due to the non-linear behaviour of the waves in very shallow water.

\section{CONCLUSIONS}

The analysis of X-band radar wave image sequences is a powerful new technique for mapping wave properties such as wavelength, direction and celerity over ranges of approximately $2 \mathrm{~km}$. These data can then be used in a bathymetric inversion to remotely map the sea bed. At present the water depths determined by the radar technique are overestimated under conditions where the waves become non-linear in their behaviour. In particular waves approaching the shore in very shallow water where the waves are starting to break are a problem. Future work will lead to corrections for the errors caused by these types of waves. The use of waterline detection methods on the radar data is also showing some potential for extending the radar mapping capabilities to intertidal areas.

\section{ACKNOWLEDGEMENTS}

The COAST3D project is funded partly by the Marine Science and Technology (MAST) RTD programme of the European Union under Contract Number MAS3CT97-0086, and partly through national funding from the UK Ministry of Agriculture Fisheries and Food research project FD0803, the UK Environmental Agency R\&D Programme), the UK Natural Environment Research Council, and the Netherlands Rijkswaterstaat. 


\section{REFERENCES}

Bell, P.S., 1998, Bathymetry derived from an analysis of X-Band marine radar images of waves. Proceedings of the Oceanology '98 conference, Brighton, England, Vol. 3, pp 535-543.

Bell, P.S., 1999, Shallow water bathymetry derived from an analysis of X-band marine radar images of waves. Coastal Engineering (37), 3-4, pp.513-527.

Borge, J.-C.N., Reichert, K. and Dittmer, J., 1999, Use of marine radar as a wave monitoring instrument. Coastal Engineering (37), 3-4, pp.331-342.

Dugan, J.P., Piotrowski, C.C. and Williams, J.Z. 2001. Water depth and surface current retrievals from airborne optical measurements of surface gravity wave dispersion. $J$. Geophysical Research, Vol. 106, No. C8, pp 16903-16915.

Hessner, K., Reichert, K. and Rosenthal, W. 1999. Mapping of sea bottom topography in shallow seas by using a nautical radar. $2^{\text {nd }}$ Symposium on Operationalization of Remote Sensing, ITC, Enschede, Netherlands, $16^{-20}$ August 1999.

Ruessink, B.G., Van Enckevort, I.M.J., Kingston, K.S. and Davidson, M.A., 2000. Analysis of observed two- and three-dimensional nearshore bar behaviour. Marine Geology, 169, pp 161-183.

Soulsby, R.L., 1998. Coastal sediment transport: The COAST3D project. Proc $26^{\text {th }}$ Int. Conf. On Coastal Engineering, ASCE, New York, pp 2548-2558. 